\title{
REPRESENTAÇÃO DE RELAÇÕES SEMÂNTICAS DE LUGAR EM SISTEMAS DE ORGANIZAÇÃO DO CONHECIMENTO
}

\section{REPRESENTATION OF SEMANTIC RELATIONSHIPS IN KNOWLEDGE ORGANIZATION SYSTEMS}

\author{
Benildes Coura Moreira dos Santos Maculana
}

\begin{abstract}
RESUMO
Introdução: Os processos de representações de domínios envolvem o estabelecimento de relações semânticas na estrutura conceitual de diferentes tipos de sistemas de organização do conhecimento (SOC). Nos SOC a associação entre os conceitos é formada a partir de diferentes relações semânticas, apresentando uma estrutura contextual que facilita a compreensão do conhecimento acumulado no domínio em questão. Dentre as diversas relações semânticas, as relações de lugar (ou espaciais) podem ser entendidas como espaços que conectam os elementos do mundo fenomenológico. Objetivo: Este artigo apresenta uma investigação sobre a representação de relações semânticas de lugar em SOC. Metodologia: Caracteriza-se como estudo exploratório e descritivo, realizado a partir da análise de proposições como meio para determinar ligações entre conceitos, expressando relações de significado entre unidades de conhecimento. Para tanto, discute-se o conceito de lugar (ou espaço) em diferentes campos do conhecimento. Resultados: Como resultado, apresenta-se o papel e as formas de representação das relações espaciais, exemplificando com a descrição de algumas iniciativas. Conclusões: A exploração da literatura e as reflexões indicam a relevância no uso das relações espaciais para enriquecer semanticamente as aplicações computacionais.
\end{abstract}

Descritores: Organização do Conhecimento. Sistemas de organização do conhecimento. Relações semânticas. Relações

\section{INTRODUÇÃO}

Os sistemas de organização do conhecimento (SOC; do inglês knowledge organization systems - KOS) englobam diversificados tipos de instrumentos de

a Doutora em Ciência da Informação pelo Programa de Pós-Graduação em Ciência da Informação da Universidade Federal de Minas Gerais (UFMG). Professora do Programa de Pós-Graduação em Gestão \& Organização do Conhecimento e do Departamento de Organização e Tratamento da Informação da Escola de Ciência da Informação da Universidade Federal de Minas Gerais (UFMG). E-mail: benildes@gmail.com. 
representação e organização do conhecimento. Quando empregados como apoio a sistemas computacionais eles são responsáveis por parcela significativa do sucesso ou não da aplicação ou serviço (HODGE, 2000). Esse termo vem sendo adotado há mais de vinte anos e sua conceitualização envolve relatar a sua função, em diferentes estudos: "O termo sistemas de organização do conhecimento pretende abranger todos os tipos de estruturas para organizar a informação e promover a gestão do conhecimento" (HODGE, 2000, p. 9); "modelam a estrutura semântica subjacente de um domínio. [...] [e] podem facilitar a descoberta e a recuperação de recursos. Eles atuam como roteiros semânticos [...] [para] usuários (seja humano ou máquina)" (TUDHOPE; KOCH, 2004, n. p.); e "são vistos como esquemas que visam organizar, gerenciar e recuperar informações" (VICKERY, 2007, n. p.).

Também Soergel (1999) conceito os SOC e traz seis funções que eles podem desempenhar, como vocabulários mono, bi ou multilíngue, seja para o entendimento humano ou para a interpretação computacional, a saber: (1) referencial semântica: mapa semântico de domínios, incluindo as inter-relações entre conceitos e seus termos; (2) comunicativa: estruturas conceituais para o ensino-aprendizagem; (3) conceitual: para apoio a pesquisadores e profissionais; (4) pragmática: estrutura conceitual para orientar a construção de classificações (de doenças, de atividades, de processos); (5) seleção: mecanismos para a busca e recuperação da informação (indexação, menus de busca, expansão de consultas, organização semântica de resultados de busca); (6) linguística: base de conhecimento para processamento de linguagem natural e desenvolvimento de software.

Quanto à sua estrutura, Zeng (2008) fornece uma sistematização linear que mostra a diversidade e níveis diferenciados de complexidade dos tipos de SOC existentes, em uma visão crescente de complexidade. Ela expõe, de modo linear, os distintos graus de controle terminológico e de representação estrutural semântica. Por sua vez, Souza, Tudhope e Almeida (2012) oferecem uma concepção mais sofisticada da tipologia dos SOC, partindo da premissa de que um mesmo tipo de instrumento pode variar em relação à sua complexidade semântica, uma vez que podem ser empregados com propósitos diferentes, 
assim como agregar elementos que não estavam em sua natureza de origem. Para os autores, esse fato dificulta encontrar consenso sobre a definição de cada um dos tipos de SOC. Eles, então, apresentam uma representação da tipologia de SOC a partir de uma taxonomia que classifica as dimensões intrínsecas (modelo ideal; aspectos essenciais e acidentais) e extrínsecas (contexto de uso) dos distintos instrumentos.

Discorrendo sobre a função e complexidade semântica dos tipos de SOC, Bratková e Kučerová (2014) destacam a diversidade dos ambientes (instituições bibliotecárias, de memória, profissionais) onde as atividades de organização da informação podem ocorrer. Para elas, a organização da informação é "qualquer atividade intencional que consiste em introduzir uma estrutura em um conhecimento já existente e registrado, com o objetivo de possibilitar seu armazenamento e acesso" (BRATKOVÁ; KUČEROVÁ, 2014, p. 2). Nesses contextos, os SOC são ferramentas que mostram o modelo da estrutura semântica daquele conjunto organizado de recursos de informação que foram armazenados no sistema (banco de dados).

As autoras também afirmam que os modos de armazenamento afetam "quase todo o ciclo de vida do conhecimento, desde a sua representação (expressão), [passando pela] comunicação, [...], publicação, processamento (identificação, descrição, análise de conteúdo, indexação, transformação)" (BRATKOVÁ; KUČEROVÁ, 2014, p. 2), chegando, finalmente, ao armazenamento propriamente dito. Elas também ressaltam que os SOC podem facilitar o acesso ao conhecimento quando forem utilizados como mecanismo para apoiar, por exemplo, a formulação das buscas pelos usuários ou mesmo a organização dos resultados obtidos nessas buscas. Nessa perspectiva, as autoras definem os SOC como "ferramentas de comunicação em rede digital, representadas atualmente pela tecnologia de Linked Open Data (LOD)", compostas por um "conjunto altamente diversificado de instâncias, muitas vezes dramaticamente diferentes, cujas características comuns podem ser difíceis de encontrar" (BRATKOVÁ; KUČEROVÁ, 2014, p. 2-3).

A tecnologia LOD se refere à possibilidade de compartilhamento irrestrito de recurso informacional encontrado na web. O LOD provém dos princípios da 
Web Semântica, sendo composto por um conjunto específico de normas, com alto grau de exigência de qualidade, que orientam o estabelecimento de ligações semânticas entre recursos de dados (SANTAREM SEGUNDO, 2015). Com isso, as ligações entre os dados disponibilizados na web "Têm significado, são links semânticos, expressam a relação entre os recursos linkados" (MARCONDES, 2012, p. 179). Para que seja possível explicitar a semântica da ligação entre os recursos, é também necessário especificar o significado desses recursos. Ou seja, é preciso que cada recurso de dado seja representado por um rótulo (ou termo), com um endereço único e individual - Uniform Resource Identifier (URI), e que seja correspondente a um conceito (significado).

Para a definição do significado de um conceito, Hjorland (2008) afirma que é preciso determinar

Que tipo de trabalho o conceito tem que fazer por nós, e de que maneira as diferentes formas de compreender este conceito podem facilitar ou contrariar o que nós queremos realizar. Quando estamos trabalhando com ferramentas terminológicas e semânticas, tais como dicionários, sistemas de classificação e tesauros, o conceito de conceito parece inevitável e os progressos na compreensão de conceitos podem influenciar a própria maneira de trabalho na Terminologia, na Biblioteconomia e Ciência da Informação e em muitas áreas afins (HJORLAND, 2008, online).

Observa-se, assim, que o conceito deve ser definido a partir da identificação de sua função dentro da estrutura conceitual de um SOC, sendo necessário modelar o conhecimento do domínio em conformidade com as necessidades informacionais que se quer resolver.

Ao desenvolver a sua Teoria do Conceito, originalmente pensada para a construção de tesauros e sistemas de classificação, Dahlberg (1978; 2006) criou um "modelo analítico idealizado para elucidar a natureza e a estrutura dos conceitos" (DAHLBERG, 1978, p. 4), sendo cada conceito uma "unidade de conhecimento". Para a autora, o conceito é formado pelo conjunto de enunciados verdadeiros (características) e necessários (para o contexto e propósito em questão) sobre um objeto (referente), que é representado por um termo (forma verbal). Szostak (2013) afirma que os termos - que expressam os conceitos sem ambiguidade, cujas definições são constituídas por meio de regras sintáticas são os elementos básicos na construção das estruturas dos SOC, pois é a partir 
deles que a conexão entre conceitos é estabelecida. Para o autor, em ambiente web a estrutura de um SOC deve ser concebida em uma linguagem composta por declarações de triplas: sujeito - predicado/propriedade - objeto.

Nesses casos, o sujeito e o objeto são representados por um termo (que está estruturado na hierarquia compartilhada do SOC), que são as coisas do mundo fenomenológico. Já o predicado/propriedade representa um dado atributo para a conexão que se estabelece entre as coisas (sujeito e objeto) - que podemos denominar de relações semânticas entre as duas entidades. Existem na literatura diversos tipos de relacionamentos que podem ser empregados para conectar conceitos, que podemos sintetiza em relações de equivalências, hierárquicas e associativas. Essas relações compõem os sistemas de conceitos que representam um domínio, uma dada realidade, ou os elementos (referentes) que coexistem neles.

Sobre essa questão, Severino (2002, p.188) afirma que um "conceito garante uma referência direta ao objeto real" e que essa "referência é dita intencional", sendo o conceito "adquirido por processos especiais de apreensão das coisas, [...] a objetos, a seres, a ideias, de maneira representativa e substitutiva". Dahlberg $(1978 ; 2006)$ declara que todo termo representa um único conceito em particular, ainda que possam existir outros termos, que sejam considerados equivalentes num dado contexto, também representantes daquele mesmo conceito. A autora acredita que assim chegamos em objetos únicos no mundo, que são distintos dos demais (coisas, fenômenos, processos, acontecimentos, atributos, entre outros). Ela afirma que "O que caracteriza os objetos individuais é a presença das formas do tempo e espaço. Os objetos individuais estão aqui e agora" (DAHLBERG, 1978, p. 101).

No âmbito da física, na Teoria da Relatividade de Einstein, a dimensão tempo-espaço significa considerar que não existe uma separação entre esses dois elementos, pois a ocorrência de um objeto só pode ser em um local e lugar, juntos (WILBER, 1991). Para Hawking (1988, p. 60), "Espaço e tempo não apenas afetam, mas também são afetados por qualquer coisa que aconteça no universo", sendo que não há como determinar o início e nem o fim do tempo (HAWKING, 2001). 
No âmbito dos eventos e espaços sociais, o tempo-espaço é a própria dimensão da realidade humana, que representa a "dimensão da experiência vivida ou da consciência" (ELIAS, 1998, p. 66). A estrutura social e econômica da sociedade perpassa, assim, a "construção de espaços geoeconômicos novos ou a redefinição de antigos espaços produtivos [que] coloca uma temporalidade nos eventos, cuja dinâmica, ou seja, o movimento, diferencia o grau de evolução de cada civilização" (VIEIRA; VIEIRA, 2002, p. 47).

No âmbito da construção de instrumentos de representação do conhecimento - os SOC - os fluxos de recursos de informação existem no tempo-espaço. E, complementando, temos o tempo-espaço dos lugares onde concretamente os fluxos de informação ocorrem. Esses lugares se concretizam a partir de necessidades distintas de usuários (ou de clientes), que são públicos em diferentes ambientes (corporativo, industrial, profissional, de lazer) - são os contextos. Como explica Roazzi (1987, p. 28), o "Significado atribuído a uma expressão verbal particular [...] [é] uma determinação prévia baseada em práticas institucionais e culturais", e, nesse sentido, numa situação comunicativa o "contexto se torna, então, um dos elementos que esclarecem a polissemia, fornecendo as chaves para a interpretação do evento (ROAZZI, 1987, p. 30).

Há de se considerar que "uma razão para o sucesso das tecnologias da Web Semântica nas ciências da vida, como a medicina, é baseada em definições canônicas. Embora possamos definir uma mão humana como tendo cinco dedos distinguíveis em uma ordem específica, [...] não há definições livres de contexto para lagos, florestas e muitos outros tipos de características geográficas. $O$ contexto [...] é largamente determinado pelo espaço e pelo tempo" (JANOWICZ, 2010, p. 26-27). E haverá outros ambientes, fora do âmbito da geografia, para os quais o contexto é desejável. Por exemplo, as informações jurídicas necessitam do contexto, já que há diferenças de abordagens de representação, dependendo do setor jurídico para o qual o serviço é modelado. Para Janowicz, (2010, p. 25), o "Espaço e tempo são relações ordenadoras fundamentais para a organização, representação e raciocínio do conhecimento". Nesses casos, vamos considerar que o espaço é a representação do lugar e o tempo se refere à sucessão de acontecimentos. Espaço e tempo são, assim, elementos distintos 
e devem ser analisados isoladamente.

Neste artigo, que se caracteriza como um estudo exploratório, bibliográfico e descritivo, busco refletir sobre a seguinte questão: qual a relevância em representar as relações de lugar em sistemas de organização do conhecimento? Conjecturando sobre isso, após esta introdução, que discorre sobre as funções e estrutura conceitual dos SOC, é apresentado o conceito de lugar (ou espaço) em diferentes campos do saber, enfatizando os dados georreferenciados, o papel e as formas de representação das relações espaciais, apresentando o exemplo de relações espaciais no tesauro Multilingual Agricultural Thesaurus (Agrovoc).

\section{CONCEITUANDO O LUGAR}

Reconhecer e fornecer informações sobre lugares é acontecimento corriqueiro e natural no cotidiano dos indivíduos. Em análises gramaticais, por exemplo, se digo que "Ruth está em frente à floricultura", essa expressão é Locativa ou Locacional:

$$
\begin{gathered}
\text { Ruth = locatum } \\
\text { floricultura = relatum } \\
\text { em frente à = relação espacial ou locativo }
\end{gathered}
$$

A frase em questão representa um modo geral de comunicação espacial entre indivíduos, que são compostas por um elemento a ser localizado (locatum; Ruth), um ponto de referência (relatum; floricultura) e a relação espacial.

O Quadro 1 mostra diferentes expressões em linguagem natural que estabelecem relações locativas (espaciais) quando analisadas gramaticalmente:

\section{QUADRO 1 - Exemplos de expressões de relações de locativas (espaciais)}

\begin{tabular}{|c|c|}
\hline Locução adverbial de lugar & Advérbios de lugar \\
\hline à esquerda & aqui \\
\hline à direita & aí \\
\hline à frente & ali \\
\hline ao lado & cá \\
\hline em cima & lá \\
\hline de fora & acolá \\
\hline por perto & além \\
\hline por aqui & longe \\
\hline
\end{tabular}




\begin{tabular}{|c|c|}
\hline Locução adverbial de lugar & Advérbios de lugar \\
\hline em volta & perto \\
\hline à tona & dentro \\
\hline à distância & adiante \\
\hline à entrada & defronte \\
\hline à saída & acima \\
\hline ao fundo & abaixo \\
\hline ao longo & atrás \\
\hline de longe & em outro lugar \\
\hline por dentro & em nenhum lugar \\
\hline na esquina & em algum lugar \\
\hline
\end{tabular}

Fonte: elaborado pela proponente, a partir da literatura.

O uso dessas expressões, em geral, são tentativas de tornar mais específicas as relações espaciais entre dois objetos, ou seja, torná-las mais precisas. $\mathrm{Na}$ linguagem natural, muitas dessas expressões estabelecem relações de equivalência de representação, tal como ocorre com "aqui", que é equivalente a "neste lugar; cá".

No âmbito da Linguística, a Teoria Generalizada dos Papéis Temáticos (TGPT), elaborada por Cançado (1995; 2000; 2003), apresenta descrições dos papéis temáticos ${ }^{1}$ espaciais, fornecendo suas propriedades semânticas. A autora classificou os papéis temáticos espaciais em seis grupos: Deslocado (de um ponto A para um ponto B), Locativo (lugar de), Fonte (início do trajeto), Meta (fim ou destino do trajeto), Origem (procedência) e Orientação (direção). Segundo a teoria, a semântica proveniente dos papéis temáticos espaciais afeta as construções (sintaxe) frasais, podendo alterar a função sintática a ser exercida por um determinado papel temático.

O conceito de lugar pode ser representado e analisado a partir de diferentes abordagens, advindas de distintas áreas. No dicionário encontramos as seguintes definições para o verbete "lugar":

S.m. 1. Espaço ocupado; sítio. 2. Espaço (2). 3. Sítio ou ponto referido a um fato. 4. Espaço próprio para determinado fim. 5. Ponto de observação; posição; posto. 6. Esfera, roda, ambiente. 7. Povoação; localidade. 8. Posição; situação. 10. Classe; categoria; ordem. 11. Ocupação; emprego; função; cargo. 12. Assento marcado e determinado. 13. Posição determinada num conjunto, numa escala, numa série; colocação. 14.

1 Papéis temáticos são os diversos papéis que um sintagma pode desempenhar em relação à ação ou ao estado descrito por um verbo (BORBA, 1996). 
Oportunidade, ensejo, vez, ocasião. 15. Tempo, folga, vaga. 16. Direção, rumo, destino. 17. Trecho ou passagem de um livro, de uma obra. 18. Geom. Lugar geométrico [...] Conjunto de pontos que satisfazem a uma ou mais condições. [...] (FERREIRA, 2009, p. 402).

Esta definição demonstra a complexidade envolvida na representação do lugar, pois qualquer estado-de-coisas acontece em um dado mundo, real ou imaginário, e está sujeito a certas situações ou operações que o localizam em um determinado quadro espacial (de lugar). Esse quadro espacial responde à pergunta: onde? As representações que denotam lugar, quando ligadas a uma expressão verbal - que denotam uma relação semântica - são o complemento locativo que servem de determinante para esse verbo.

Podemos pensar o lugar ligado a três dimensões: local (location), localidade (locale) e senso de lugar (sense of place) (CRESSWELL, 2015). O local (location) seria o instanciamento de um espaço ocupado e delimitado, tal como Belo Horizonte (aqui; here) e Nova lorque (lá; there), que são locais estáticos. Mas podemos ter também locais não estáticos, como, por exemplo, um dado barco que está navegando em uma determinada posição, em um determinado mar, por exemplo (CRESSWELL, 2015).

A localidade (locale) estaria mais ligada a uma noção formal para indicar o local ou ambiente onde coisas acontecem, um local geral e não um local exato, tal como: "vamos a uma ilha tropical para fazer o casamento"; ou "programaremos uma viagem a uma praia" (CRESSWELL, 2015). Não é uma localização absoluta (exata; latitude e longitude) e nem relativa (relacionado a outros lugares por meio da água, terra ou tecnologia) de um local. É quase como se fosse uma classe de maior abstração de coisas semelhantes.

Já o senso de lugar (sense of place) é a dimensão que faz referência a um significado especial e/ou emocional, pessoal ou compartilhado, consciente ou não, de uma pessoa ou animal, que está estreitamente ligado a um lugar (location) específico (CRESSWELL, 2015). Podem ser imagens (fotografias) ou filmes sobre lugares, cenas, paisagens ou objetos, que levam as pessoas a manter uma forte identidade que evocam sentimentos e emoções nelas. O lugar adquire, nessa situação, atributos particulares (afetivo, simbólico, de pertencimento), criando uma rede sócio-espacial. Esse elemento é estudado em 
investigações no campo da geografia humanística, por exemplo.

O conceito de lugar está muito ligado à noção de espaço, uma vez que "viver, para o homem, é produzir espaço. [...] A forma de vida do homem é o processo de criação do espaço" (SANTOS, 1996, p. 163). Trazendo a noção de Newton, numa visão filosófica, Kant (1965, p. 39) considera que "Todas as coisas, como fenômenos externos, estão justapostas no espaço". O espaço é, assim, discutido em diferentes áreas do conhecimento, sob distintas abordagens. E nos SOC, em geral, denominamos esse tipo de ligação entre conceitos de relação espacial.

Na visão da Geografia crítica, o espaço se forma por uma intencionalidade social e é "Definido como um conjunto indissociável de sistemas de objetos e de sistemas de ações" (SANTOS, 2009, p. 21). Para o autor, os objetos e ações se mantêm "Reunidos numa lógica que é, ao mesmo tempo, a lógica da história passada (sua datação, sua realidade material, sua causação original) e a lógica da atualidade (seu funcionamento e sua significação presentes)" (SANTOS, 2009, p. 77-78). Temos novamente a concepção de que espaço e tempo são noções que acompanham os fenômenos que envolvem todas as coisas do mundo, inter-relacionando-as. Considerando que as relações espaciais têm relevância em diferentes contextos de representação de modelos de mundo, tal como nos SOC, a próxima seção traz discussões acerca desse elemento.

\section{PAPEL DAS RELAÇÕES ESPACIAIS}

Fazendo uma síntese sobre as relações espaciais na literatura no campo de Sistema de Informação Geográfica (SIG), Ferreira (2019, p. 45-46) as agrupa em três categorias principais: topológicas (relacionamentos entre os objetos geográficos que são invariantes à rotação, à translação e à escala), de direções (ordinais; relações referentes a transformações de translação e escalonamento do referencial) e de distâncias (relações métricas; transformações de translação e rotação, e de escalonamento do referencial). Cada um desses tipos de relação espacial alimentam e estruturam um banco de dados georreferenciados que possibilitam o processamento de informações para diversificados fins.

Borges (2002, p. 5) afirma que o "espaço geográfico é o meio físico onde 
as entidades geográficas coexistem", sendo que a entidade geográfica é qualquer entidade do mundo real que mantém relações espaciais entre si. A autora destaca que essas entidades são capturas a partir de dados georreferenciados, que descrevem e localizam em uma dada dimensão espacial (lugar-tempo) os fenômenos dos modelos de mundo. As características espaciais desses dados "informam a posição geográfica do fenômeno e sua geometria" (BORGES, 2002, p. 5). Segundo a autora, os dados georreferenciados podem ter propriedades geométricas (relações métricas: pontos, linhas, polígonos, entre outros) e topológicas (relações com base em posições relativas dos objetos no espaço: conectividade, orientação, adjacência e contenção).

Muitas das relações espaciais (dentro de; através; perto; longe) são apresentadas por expressões em linguagem natural (ver Quadro 1), e carregam um forte fator cognitivo humano, não podendo ser implementadas em aplicações computacionais, sendo preciso representá-las formalmente (BORGES, 2002). Por outro lado, uma mesma realidade pode ser representada a partir de diferentes modelos de abstrações, pois,

Um rio, por exemplo, pode ser percebido como um espaço entre suas margens, como um polígono de água ou como um fluxo formando a rede hidrográfica, dependendo das circunstâncias e da interpretação do observador. Esse tratamento diferente para uma mesma entidade geográfica é conhecido como múltipla representação e está associado às necessidades específicas de diferentes aplicações (BORGES, 2002, p. 7).

Assim, as relações de lugar representadas em um SOC no domínio hidrográfico poderão acolher distintas perspectivas de representações, dependendo do propósito que vai atender.

Barcellos e Machado (1998) destacam que os dados georreferenciados são mecanismos importantes na determinação da qualidade de vida, da saúde e ambiental, uma vez que possuem três propriedades: (a) capacidade de apresentar informações complexas (cartográficas); (b) habilidade para a integração de objetos espaciais e seus atributos; e (c) competência para análises de dados espaciais. Citando Ávila-Pires (1983), o autor afirma que o objetivo da "geografia médica é elucidar as causas e os fatores que condicionam os padrões de distribuição geográfica das doenças e das condições que afetam os índices 
de saúde e de vida" (BARCELLOS; MACHADO, 1998, p. 104), tendo em vista mapear e correlacionar as ocorrências. Nas representações espaciais, segundo o autor, também é necessário considerar, que "dentro da mesma região, índios e garimpeiros possuem modos de vida, relacionados à sua inserção social, que produzem perfis epidemiológicos divergentes" (BARCELLOS; MACHADO, 1998, p. 106), o que exige agregar dados culturais, que são objeto de estudo da geografia humanística.

Por sua vez, na proteção de recursos naturais e ambientais, tal como às cavidades naturais subterrâneas, que é amparada no Brasil pelo Decreto $\mathrm{n}^{\circ}$ 6.640 , de 07/11/2008, as políticas públicas para regular, nessas áreas, atividades espeleológicas, étnico-culturais, turísticas, recreativas e educativas exigem uma "Efetiva quantificação e reconhecimento da distribuição das cavidades localizadas no território nacional" (GALVÃO; GALVÃO, 2012, p. 39), ou seja, é necessária a determinação de suas localidades.

Ortiz et al. (2006) discorrem sobre a importância da representação de relações espaciais, com o uso de dados georreferenciados, na gestão da produção florestal. Isso permite "avaliações, análises e simulações de natureza espacial, em função de variáveis relacionadas ao solo, ao relevo, ao clima, às plantas, às intervenções humanas etc., subsidiando as tomadas de decisão nos diversos níveis" (ORTIZ et al., 2006, p. 68). Segundo os autores, essas informações norteiam as intervenções pontuais para manter a produtividade florestal, pois "o mercado demanda madeira de boa qualidade e a indústria florestal visa obter maior lucratividade" (ORTIZ et al., 2006, p. 68). Para além da lucratividade, os autores ressaltam o fator da sustentabilidade, uma vez que a identificação de limitações de produção de uma determinada "Área ou região, torna-se essencial quando se tem como objetivo o manejo racional da floresta e do solo, evitando a exaustão química e a degradação dos atributos físicos desse último, visando à máxima produtividade sustentável" (ORTIZ et al., 2006, p. 68).

$\mathrm{Na}$ exploração agrícola vem sendo utilizados dados sobre a variabilidade espacial, que determinam os atributos do solo e da cultura de um espaço ou área, permitindo o diagnóstico de fatores pontuais que limitam a exploração e a produtividade de um dado lugar (ZONTA, 2014). Com isso é possível indicar 
opções de manejo de exploração agrícola adequadas a cada região ou espaço de cultivo, abordagem que está sendo aplicada pela agricultura de precisão.

Como exemplo de construção de SOC do tipo ontologia, Costa (2018, p. 8) propôs um método para o enriquecimento semântico de Informação Geográfica Voluntária (VGI), que "Refere-se a um tipo de informação com geolocalização, que é coletada e/ou compartilhada voluntariamente por meio da Internet", para alimentar uma ontologia. A autora utilizou como base as relações espaciais de proximidade, o que possibilitou ao sistema fazer análises semânticas a partir de tais dados, além de "encontrar ou resolver inconsistências e ambiguidades, melhorando a qualidade dos dados produzidos pelo usuário" (COSTA, 2018, p. 21).

Esses exemplos não esgotam os papeis que são desempenhados pelas relações espaciais nas aplicações computacionais, mas evidenciam a relevância da coleta desse tipo de informação para a correta interpretação de uma realidade. A seção a seguir apresenta as formas de representação para relações espaciais dos tipos topológicos, métricos e direcionais, um exemplo de aplicação na recuperação de imagens e as relações espaciais na estrutura do tesauro Agrovoc.

\subsection{REPRESENTAÇão dAs RELAÇõES EsPaCiaIS}

As relações espaciais são compostas por dados topológicos, métricos e direcionais, podendo demonstrar diferentes tipos de informações, conforme apresentado nas Figuras 1 e 2 .

FIGURA 1 - Informações sobre o campo

\begin{tabular}{|c|c|c|c|c|}
\hline $\begin{array}{l}\text { Rede Triangular } \\
\text { Irregular }\end{array}$ & Isolinha & $\begin{array}{l}\text { Polígonos } \\
\text { Adjacentes }\end{array}$ & Tesselação & Amostragem \\
\hline \begin{tabular}{|l|l} 
Name & Nome Classe \\
da
\end{tabular} & \begin{tabular}{|l|l|} 
Nome & $\begin{array}{l}\text { Nome } \\
\text { da Classe }\end{array}$ \\
\end{tabular} & Name $\begin{array}{l}\text { Nome } \\
\text { da Classe }\end{array}$ & \begin{tabular}{|l|l|} 
典册 & $\begin{array}{l}\text { Nome } \\
\text { da Classe }\end{array}$ \\
\end{tabular} & \begin{tabular}{l|l}
$\because$ & Nome \\
& da Classe
\end{tabular} \\
\hline Atributos Gráficos & Atributos Gráficos & Atributos Gráficos & Atributos Gráficos & Atributos Gráficos \\
\hline Atributos & Atributos & Atributos & Atributos & Atributos \\
\hline Operações & Operações & Operações & Operações & Operações \\
\hline Ex: TIN & $\begin{array}{l}\text { Ex: Curvas de } \\
\text { Nível }\end{array}$ & $\begin{array}{l}\text { Ex: Divisão de } \\
\text { Bairros }\end{array}$ & $\begin{array}{l}\text { Ex: Imagem de } \\
\text { Satélite }\end{array}$ & $\begin{array}{l}\text { Ex: Pontos } \\
\text { Cotados }\end{array}$ \\
\hline
\end{tabular}

Fonte: SPRING (2006, n. p.). 


\section{FIGURA 2 - Informações sobre espaços e fronteiras}

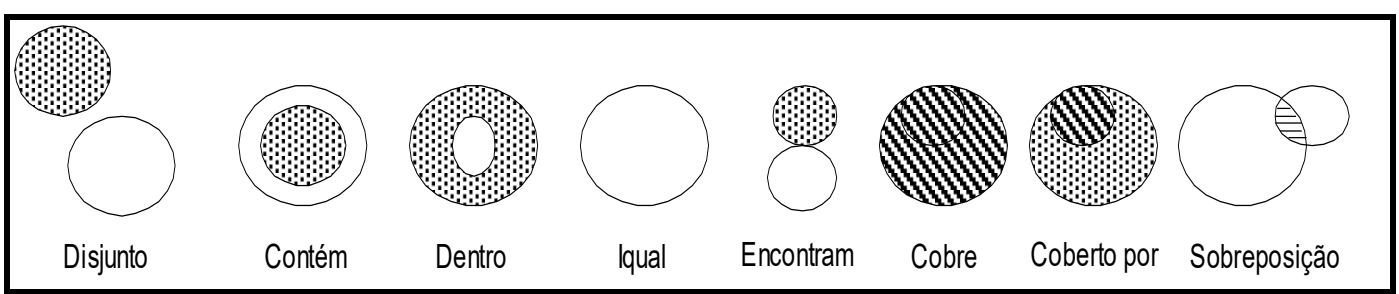

Fonte: SPRING (2006, n. p.).

Esses dados podem ser subdivididos em mapas temáticos, cadastrais, de redes, de modelos numéricos de terrenos ou de imagens de satélites (CASANOVA et al., 2005), com distintas formas de representação de relações espaciais, conforme Figura 3.

FIGURA 3 - Diferentes representações de relações espaciais

\begin{tabular}{|c|c|}
\hline LINHALINHA & \\
\hline Disjunto & $-B$ \\
\hline Toca & $\longrightarrow$ \\
\hline Cruza & \\
\hline Coincidente & A, B \\
\hline Acima/Abaixo & $\stackrel{-}{\longrightarrow}$ \\
\hline Adjacente & 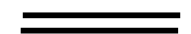 \\
\hline Pero de & $\stackrel{d}{\leftrightarrow}$ \\
\hline Entre & 1 \\
\hline Paralelo a & $\stackrel{\mathrm{d}}{\leftrightarrow}$ \\
\hline Sobre & A, B \\
\hline
\end{tabular}

\begin{tabular}{|c|c|}
\hline LINHA \\
POLIGONO
\end{tabular}

\begin{tabular}{|c|c|}
\hline LINHAIPONTO \\
\hline Disjunto & \\
\hline Toca/Adjacente & \\
\hline Perto de & \\
\hline Sobre & \\
\hline Acima/Abaixo & \\
\hline
\end{tabular}

\begin{tabular}{|c|}
\hline PONTO/ \\
POLIGONO \\
\hline Disjunto \\
\hline Adjacente/Toca \\
\hline Perto de \\
\hline Dentro de \\
\hline Acima/Abaixo \\
\hline Em frente a \\
\hline
\end{tabular}

\begin{tabular}{|c|c|}
\hline PONTO/PONTO & \\
\hline Disjunto & $\bullet$ \\
\hline Adjacente/Toca & $\bullet$ \\
\hline Perto de & \\
\hline Coincidente & d \\
\hline Acima/Abaixo \\
\hline Em frente a \\
\hline
\end{tabular}

Fonte: SPRING (2006, n. p.). 
Nos mapas temáticos, por exemplo, as regiões geográficas são indicadas por um ou mais polígonos, mostrando, entre outros elementos, o uso do solo e os limites entre regiões (arcos) (SPRING, 2006). Por sua vez, os mapas cadastrais de objetos, tal como de lotes, por exemplo, indicam atributos com informações sobre o dono, localização, valor venal, Imposto Predial e Territorial Urbano (IPTU) devido, entre outros dados (SPRING, 2006). Os dados de redes possuem características próprias e estão atreladas às questões culturais, pois são "[...] resultado direto da intervenção humana sobre o meio-ambiente" (SPRING, 2006, n. p.). Já os modelos numéricos de terreno (ou MNT) representam grandezas que variam continuamente no espaço, e são geralmente ligadas à altimetria e outros fenômenos tais como variáveis geofísicas e geoquímicas (SPRING, 2006). Por fim, as imagens capturadas por satélite (ou via aéreas ou por escâneres aerotransportados) contêm elementos de imagem (pixe/s) que possibilitam identificar objetos geográficos que podem ser individualizados a partir de diferentes técnicas (tais como resoluções espectral, espacial, temporal).

Como exemplo, Santos (2017, p. 95) construiu relações espaciais utilizando atributos extraídos de imagens, "que foram expressas em preposições espaciais". O autor, "partindo dos dados de baixo nível, referentes à intensidade dos pixels, os distintos objetos existentes em uma imagem são identificados e combinados em pares para que se possa definir uma relação espacial" (SANTOS, 2017, p. 95). O reconhecimento das relações espaciais foi adotado para estender e refinar uma ontologia, usada como base de conhecimento em um sistema de recuperação de imagens. "Assim, o sistema é capaz de abstrair novas relações não vistas anteriormente e adicionalmente expressar relações cuja cardinalidade seja diferente das relações binárias originais" (SANTOS, 2017, p. 95), pois a ontologia foi capaz de fazer inferências.

Para realizar o trabalho, Santos (2017, p. 95) usou a técnica da segmentação semântica, que permite "Identificar os objetos existentes em uma imagem". O autor segmentou os objetos que integram a imagem e estabeleceu relações espaciais entre cada par de objetos segmentados, em relações binárias. Para fazer a divisão em segmentos o autor empregou redes neurais 
convolucionais (Convolutional Neural Network - CNN), que é um algoritmo de aprendizado profundo capaz de análises mais refinadas do que as conseguidas por algoritmos de classificação. As relações espaciais foram convertidas em preposições espaciais, quando foi necessário definir a topologia. Para isso, o autor adotou o Region Connection Calculus (RCC), que é composto por oito tipos diferentes de relações espaciais. Como resultado, o autor atingiu o propósito estipulado, ainda que de maneira restrita, e como trabalhos futuros ele sugere utilizar um sistema de multiagentes, com vistas a possibilitar ao sistema tirar maior proveito inferencial a partir das informações de localização.

Para exemplificar a representação de relações espaciais em SOC, apresento o tesauro Multilingual Agricultural Thesaurus (Agrovoc), do domínio da agricultura, que converteu a sua estrutura conceitual em Simple Knowledge Organisation System (SKOS), tendo em vista expressar, de maneira mais formalizada, as relações entre conceitos e termos. A conversão permitiu explicitar as relações, tornando-as mais semanticamente refinadas. Dentre as 176 (cento e setenta e seis) relações específicas - o Agrontology ${ }^{2}$ - que compõem a estrutura do tesauro, existem pelo menos 17 (dezessete) relações que podem ser reconhecidas como do tipo espacial, conforme Quadro 2.

\section{QUADRO 2 - Relações espaciais presentes na estrutura do tesauro Agrovoc}

\begin{tabular}{|l|}
\hline \multicolumn{1}{|c|}{ Relações espaciais no Agrovoc } \\
\hline (01) relação espacial \\
Definição: $X$ <relação espacial>. X é cada uma das relações que \\
permitem a construção e a representação de um espaço, local, território \\
ou região. Nota: as relações podem ser topográficas (ex.: lado, vizinho, \\
dentro, etc.), projetivas (ex.: direita, esquerda, ao sul, etc.) e métricas \\
(distâncias e coordenadas). \\
tem característica: simétrica \\
tem suprapropriedade: relacional \\
tem subpropriedade: rodeado por / rodeia \\
é inversa de: relação espacial / relação espacial \\
\hline (02) rodeado por \\
Definição: X <rodeado por> Y. X é um objeto que está fisicamente \\
rodeado por Y. \\
tem supra-propriedade: relação espacial \\
é inversa de: rodeia
\end{tabular}

2 Disponível em: http://aims.fao.org/sites/default/files/uploads/file/aos/agrontology/index.htm. 


\begin{tabular}{|c|}
\hline Relações espaciais no Agrovoc \\
\hline $\begin{array}{l}\text { (03) rodeia } \\
\text { Definição: } Y \text { <rodeia> X. X é objeto que está fisicamente rodeado por } Y \text {. } \\
\text { tem supra-propriedade: relação espacial } \\
\text { é inversa de: rodeado por }\end{array}$ \\
\hline $\begin{array}{l}\text { (04) tem composição } \\
\text { Definição: } Y<\text { tem composição> } X . X \text { é parte de um todo } Y \text {, ou } X \\
\text { decompõe } Y \text { de alguma maneira, seja no seu aspecto ou em sua forma, } \\
\text { sendo que } X \text { não está inerentemente misturado em } Y \text {. } \\
\text { tem supra-propriedade: relacional } \\
\quad \text { é inversa de: é composição de }\end{array}$ \\
\hline $\begin{array}{l}\text { (05) é composição de } \\
\text { Definição: } Y \text { <é composição de> } X . X \text { é parte de um todo } Y \text {, ou } X \\
\text { decompõe } Y \text { de alguma maneira, seja no seu aspecto ou em sua forma, } \\
\text { sendo que } X \text { não está inerentemente misturado em } Y \text {. } \\
\quad \text { tem suprapropriedade: relacional } \\
\quad \text { é inversa de: tem composição }\end{array}$ \\
\hline $\begin{array}{l}\text { (06) cresce em (CONSTITUTIVA) } \\
\text { Definição: } X<\text { <resce em> Y. Um táxon } X \text { cresce em um ambiente } Y \text {. } \\
\text { Usar essa relação para indicar uma planta e seu domínio conexo } \\
\text { (complementar). } \\
\quad \text { tem suprapropriedade: relacional } \\
\quad \text { é inversa de: é ambiente de crescimento para }\end{array}$ \\
\hline $\begin{array}{l}\text { (07) é ambiente de crescimento para (CONSTITUTIVO) } \\
\text { Definição: Y <é um ambiente de crescimento para> X. X é um táxon que } \\
\text { cresce em um ambiente Y. Nota: essa relação deve ser usada para } \\
\text { indicar uma planta e seu domínio conexo (complementar). } \\
\text { tem suprapropriedade: relacional } \\
\text { é inversa de: cresce em }\end{array}$ \\
\hline $\begin{array}{l}\text { (08) tem parte } \\
\text { Definição: } X<\text { tem parte> Y. Y é uma parte do todo X. Nota: essa relação } \\
\text { deve ser usada quando nenhuma das situações das relações } \\
\text { hierárquicas partitivas puder ser aplicada. } \\
\text { tem suprapropriedade: relacional } \\
\text { tem subpropriedade: tem componente, é composto de, } \\
\quad \text { espacialmente inclui } \\
\quad \text { é inversa de: é parte de }\end{array}$ \\
\hline $\begin{array}{l}\text { (09) é parte de } \\
\text { Definição: } Y<\text { <é parte de> X. Y é uma parte do todo X. Nota: essa } \\
\text { relação deve ser usada quando nenhuma das situações das relações } \\
\text { hierárquicas partitivas puder ser aplicada. } \\
\text { tem suprapropriedade: relacional } \\
\text { tem subpropriedade: composto, componente de, espacialmente } \\
\text { incluído em } \\
\text { é inversa de: tem parte }\end{array}$ \\
\hline $\begin{array}{l}\text { (10) compõe } \\
\text { Definição: } Y \text { <compõe> X. Y é um composto de } X \text {, onde } Y \text { consiste no } \\
\text { material ou substância de que } X \text { é feito. } \\
\text { tem supra-propriedade: é parte de } \\
\quad \text { é inversa de: é composto de }\end{array}$ \\
\hline
\end{tabular}




\begin{tabular}{|c|}
\hline Relações espaciais no Agrovoc \\
\hline $\begin{array}{l}\text { (11) é composto de } \\
\text { Definição: } X<\text { <é composto de> } Y . Y \text { é um composto de } X \text {, onde } Y \\
\text { consiste no material ou substância de que } X \text { é feito. } \\
\text { tem supra-propriedade: tem parte de } \\
\text { é inversa de: compõe }\end{array}$ \\
\hline $\begin{array}{l}\text { (12) tem componente } \\
\text { Definição: } Y<\text { tem componente> } X . X \text { é parte de um todo } Y \text {, sendo que } X \\
\text { também tem existência independente de } Y \text {. } \\
\text { tem supra-propriedade: tem parte de } \\
\text { é inversa de: é componente de }\end{array}$ \\
\hline $\begin{array}{l}\text { (13) é componente de } \\
\text { Definição: } X<\text { <é componente de> } Y . X \text { é parte de um todo } Y \text {, sendo que } \\
X \text { também tem existência independente de } Y \text {. } \\
\text { tem supra-propriedade: é parte de } \\
\quad \text { é inversa de: tem componente }\end{array}$ \\
\hline $\begin{array}{l}\text { (14) espacialmente incluído em } \\
\text { Definição: } Y \text { <é espacialmente incluído em> X. Y é uma parte inerente } \\
\text { ou inalienável de } X \text {, sendo que } Y \text { é aquilo que está intimamente unido a } \\
\text { X, pois diz respeito ao próprio ser X. Ou seja, Y é uma parte de X } \\
\text { (animado ou inanimado) e que é inseparável ou intrínseco de X por } \\
\text { natureza. } \\
\quad \text { tem supra-propriedade: é parte de } \\
\quad \text { é inversa de: espacialmente inclui }\end{array}$ \\
\hline $\begin{array}{l}\text { (15) espacialmente inclui } \\
\text { Definição: } X \text { <espacialmente inclui> } Y \text {. Y é uma parte inerente ou } \\
\text { inalienável de } X \text {, sendo que } Y \text { é aquilo que está intimamente unido a } X \text {, } \\
\text { pois diz respeito ao próprio ser } X \text {. Ou seja, } Y \text { é uma parte de } X \text { (animado } \\
\text { ou inanimado) e que é inseparável ou intrínseco de } X \text { por natureza. } \\
\quad \text { tem supra-propriedade: é parte de } \\
\quad \text { é inversa de: espacialmente incluído em }\end{array}$ \\
\hline $\begin{array}{l}\text { (16) é membro de } \\
\text { Definição: } X<\text { <é membro de> } Y . X \text { é um membro ou um elemento que faz } \\
\text { parte de } Y \text {, sendo que } Y \text { é uma entidade coletiva ou individual, social ou } \\
\text { política. } \\
\quad \text { tem supra-propriedade: relacional } \\
\quad \text { é inversa de: tem membro }\end{array}$ \\
\hline $\begin{array}{l}\text { (17) tem membro } \\
\text { Definição: } Y<\text { tem membro> } X . X \text { é um membro ou um elemento que faz } \\
\text { parte de } Y \text {, sendo que } Y \text { é uma entidade coletiva ou individual, social ou } \\
\text { política. } \\
\quad \text { tem supra-propriedade: relacional } \\
\quad \text { é inversa de: é membro de }\end{array}$ \\
\hline
\end{tabular}

Fonte: extraído de Maculan (2015, p. 297-314).

Observa-se que há entre as 17 relações, as de <parte de $>$ como tipo de relações espaciais. Isso é corroborado por Sales, Campos e Gomes (2008), que destacam que as relações parte-todo, que ocorrem entre o todo e suas partes, assim como entre as próprias partes, são relações espaciais. No âmbito do Gene 
Ontology, as autoras ainda encontraram outras relações espaciais, tais como $<$ parte externa $>$, <parte interna $>$, <parte em torno de $>$ e < parte dentro de $>$.

Iniciativas de refinamento de relações na estrutura de tesauros, como ocorreu na estrutura do Agrovoc, não são comuns, pois isso agrega ao instrumento características de explicitação de relações semânticas que, em geral, são encontradas em ontologias. Esse fato reforça a constatação de Souza, Tudhope e Almeida (2012) quando destacam a dificuldade em haver uma definição consensual para os diferentes tipos de SOC.

\section{CONSIDERAÇÕES FINAIS}

Neste artigo houve descrição e reflexão sobre o papel das relações para a coleta de dados de lugar (ou espaço) para o enriquecimento de bases de conhecimento, sobretudo em aplicações de sistemas inteligentes. Os exemplos recuperados na literatura evidenciam que a construção de sistemas de informação vem empregando dados georreferenciados para o refinamento semântico de sua base de conhecimento. Também foram apresentadas formas de representação dessas relações espaciais (de lugar) na construção de instrumentos de representação da informação - os SOC, dando foco nas representações de áreas geográficas.

As iniciativas de aplicações computacionais com dados georreferenciados não são novidade na área da Computação, mas verifica-se que no campo de estudos da Ciência da Informação a representação e uso das relações espaciais em SOC ainda carecem de atenção. Considero que neste campo é preciso investigações sobre $\circ$ fluxo de informações que serão base para 0 desenvolvimento de soluções que possam atender às diversas necessidades informacionais de diferentes usuários sobre questões tais como recursos minerais, lugares turísticos, cidades inteligentes, agricultura de precisão ou cartografia. 


\section{REFERÊNCIAS}

AVILA-PIRES, F. Princípios de ecologia humana. Porto Alegre: Editora da Universidade Federal do Rio Grande do Sul, 1983.

BARCELLOS, C.; MACHADO, J. M. H. A organização espacial condiciona as relações entre ambiente e saúde: o exemplo da exposição ao mercúrio em uma fábrica de lâmpadas fluorescentes. Ciência da Saúde Coletiva, Rio de Janeiro, v. 3, n. 2, p. 103-113, 1998.

BORBA, F. S. Uma gramática de valências para o português. São Paulo: Ática, 1996.

BORGES, K. A. V. Curso de especialização em geoprocessamento. Belo Horzonte, UFMG, 2002.

BRATKOVÁ, E.; KUČEROVÁ, H. Knowledge organization systems and their typology. Revue of Librarianship, v. 25, n. 2, p. 1-25, 2014.

CANÇADO, M. A hierarquia temática e o português brasileiro. Revista Letras, Curitiba, v. 61, Especial, p. 17-43, 2003.

CANÇADO, M. A semântica em uma teoria gramatical. Revista de estudos da linguagem, Belo Horizonte, v. 2, n .5, p. 82-102, 2000.

CANÇADO, M. Verbos psicológicos: a relevância dos papéis temáticos vistos sob a ótica de uma semântica representacional. 1995. Tese (Doutorado em Letras) - Universidade de Campinas. São Paulo: IEL/ UNICAMP, 1995.

CASANOVA, M.; CÂMARA, G., DAVIS, C.; VINHAS, L.; RIBEIRO, G. (org.). Bancos de dados geográficos. São José dos Campos: MundoGEO, 2005.

COSTA, L. S. Enriquecimento semântico de informação geográfica voluntária utilizando Linked Data e tesauro. 2018. 91 f. Dissertação (Mestrado em Ciência da Computação) - Programa de Pós-Graduação em Ciência da Computação, Universidade Federal de Viçosa. Viçosa Minas Gerais, 2018.

CRESSWELL, T. Place: an introduction. 2. ed. Malden, MA: Wiley Blackwell, 2015.

DAHLBERG, I. Knowledge organization: a new science? Knowledge

Organization, Frankfurt, v. 33, n. 1, p. 11-19, 2006.

DAHLBERG, I. Teoria do conceito. Tradução Astério Tavares Campos. Ci. Inf., Rio de Janeiro, v. 7, n. 2, p. 101-107, 1978.

ELIAS, N. Sobre o tempo. Rio de Janeiro: Zahar, 1998.

FERREIRA, A. B. H. Novo dicionário Aurélio da língua portuguesa. 4. ed. Curitiba: Positivo, 2009. 
FERREIRA, M. E. S. Proposição de um conjunto de relações espaciais para tarefas de descrições espaciais. 2019. $166 \mathrm{f}$. Tese (Doutorado em Ciências Geodésicas) - Programa de Pós-Graduação em Ciências Geodésicas, Departamento de Geomática, Setor de Ciências da Terra da Universidade Federal do Paraná. Curitiba, 2019.

GALVÃO, A. L. C. O.; GALVÃO, W. S. As relações espaciais entre os dados de localização de cavernas e as Ottobacias: base hidrográfica geocodificada do Brasil. Revista Brasileira de Espeleologia, v. 2, n. 2, p. 38-56, 2012.

HAWKING, S. O universo numa casca de noz. São Paulo: Mandarim, 2001.

HAWKING, S. Uma breve história do tempo: do Big Bang aos buracos negros. Rio de Janeiro: Rocco, 1988.

HJORLAND, B. Concept in knowledge organization (KO). The epistemological lifeboat, 2008.

HODGE, G. Systems of Knowledge Organization for Digital Libraries: Beyond Traditional Authority Files. Washington: Council on Library and Information Resources. 2000.

JANOWICZ, K. The role of space and time for knowledge organization on the semantic web. Semantic Web Interoperability, Usability, Applicability, v. 1, n. 1-2, p. 25-32, jun. 2010.

KANT, E. Crítica da razão pura. 4. ed. São Paulo: Brasil Editora, 1965.

MACULAN, B. C. M. S. Estudo e aplicação de metodologia para

reengenharia de tesauro: remodelagem do THESAGRO. 2015. $345 \mathrm{f}$. Tese (Doutorado) - Universidade Federal de Minas Gerais, Escola de Ciência da Informação, 2015.

MARCONDES, C. H. Linked data: dados interligados e interoperabilidade entre arquivos, bibliotecas e museus na web. Encontros Bibli: Revista Eletrônica de Biblioteconomia e Ciência da Informação, v. 17, n. 34, p. 171-192, maio/ago., 2012.

ORTIZ, J. L.; VETTORAZZI, C. A., COUTO, H. T. Z.; GONÇALVES, J. L. M. Relações espaciais entre o potencial produtivo de um povoamento de eucalipto e atributos do solo e do relevo. Scientia Forestalis, n. 72, p. 67-79, dez. 2006.

ROAZZI, A. O desenvolvimento individual, o contexto social e a prática de pesquisa. Psicologia: Ciência e Profissão, Brasília, v. 7, n. 2, p. 27-33, 1987.

SALES, L. F.; CAMPOS, M. L. A; GOMES, H. E. Ontologias de domínio: um estudo das relações conceituais. Perspectivas em Ciência da Informação, Belo Horizonte, v. 13, n. 2, p. 62-76, ago. 2008.

SANTAREM SEGUNDO, J. E. Web semântica, dados ligados e dados abertos: uma visão dos desafios do Brasil frente às iniciativas internacionais. In: XVI 
ENCONTRO NACIONAL DE PESQUISA EM CIÊNCIA DA INFORMAÇÃO, 16. 26 a 30 de outubro de 2015, João Pessoa/PB. Anais [...] João Pessoa/PB:

UFPB, 2015.

SANTOS, D. N. Representação e recuperação de imagens por meio de relações espaciais entre objetos. 2017.115 f. Tese (Doutorado em

Engenharia Elétrica: área de concentração em Inteligência Artificial Aplicada à Automação) - Centro Universitário da Fundação Educacional Inaciana Padre Sabóia de Medeiros (FEI). São Bernardo do Campo, FEI, 2017.

SANTOS, M. A Natureza do espaço: técnica e tempo; razão e emoção. São Paulo: Editora da Universidade de São Paulo, 2009.

SANTOS, M. Metamorfose do espaço habitado. 4. ed. São Paulo: Hucitec, 1996.

SEVERINO, A. J. Metodologia do trabalho científico. 22. ed. São Paulo: Editora Cortez, 2002.

SOERGEL, D. The rise of ontologies or the reinvention of classification. Journal of the American Society of Information Science, v. 50, n. 12, p. 1119-1120, 1999.

SOUZA, R. R.; TUDHOPE, D.; ALMEIDA, M. B. Towards a taxonomy of KOS: dimensions for classifying knowledge organization systems. Knowledge Organization, Frankfurt, v. 39, n. 3, 2012.

SPRING. Manuais: tutorial de geoprocessamento. Brasília: DPI/INPE, 2006. (Sistema de Informações Geográficas).

SZOSTAK, R. Classification, ontology, and the Semantic Web. Advances in Classification Research, v. 24, n. 1, 2013.

TUDHOPE, D.; KOCH, T. New applications of knowledge organization systems: introduction to a special issue. Journal of digital information, v. 4, n. 4, 2004.

VICKERY, B. C. A note on knowledge organization. Site Lifeboat for Knowledge Organization, [S. I.: s. n], [2007]. Disponível em:

http://www.iva.dk/bh/lifeboat_ko/concepts/Vickery_a_note_on_knowledge_orga nisation.htm. Acesso em: 11 jun. 2019.

VIEIRA, E. F.; VIEIRA, M. M. F. Geoestratégia dos espaços econômicos: o paradigma espaço-tempo na gestão de territórios globais. In: FISCHER, T. (org.). Gestão do desenvolvimento e poderes locais: marcos teóricos e avaliação.

Salvador: Casa da Qualidade, 2002.

WILBER, K. A consciência sem fronteiras. São Paulo: Cultrix, 1991.

ZENG, M. L. Knowledge organization systems (KOS). Knowledge

Organization, Frankfurt, v. 35, n. 2-3, p. 160-182, 2008. 
ZONTA, J. H., BRANDÃO, Z. N., MEDEIROS, J. C., SANA, R. S., SOFIATTI, V. Variabilidade espacial da fertilidade do solo em área cultivada com algodoeiro no Cerrado do Brasil. Revista Brasileira de Engenharia Agrícola e Ambiental, v. 18, n. 6, p. 595602, 2014.

\title{
REPRESENTATION OF SEMANTIC RELATIONSHIPS IN KNOWLEDGE ORGANIZATION SYSTEMS
}

\begin{abstract}
Introduction: Domain representation processes involve the establishment of semantic relationships in the conceptual framework of different types of knowledge organization systems (SOC). In SOC, the association between concepts is formed from different semantic relations, presenting a contextual structure that facilitates the understanding of the accumulated knowledge in the domain in question. Among the various semantic relations, the relations of place (or spatial) can be understood as spaces that connect the elements of the phenomenological world. Objective: This paper presents an investigation into the representation of semantic place relations in SOC. Methodology: It is characterized as an exploratory and descriptive study, conducted from the analysis of propositions to determine links between concepts, expressing relationships of meaning between knowledge units. To this end, we discuss the concept of place (or space) in different fields of knowledge, based on three place approaches: the mythical, the pragmatic and the abstract. Results: As result the role and forms of representation of spatial relations are presented, exemplifying with the description of some initiatives. Conclusions: The exploration of the literature and the reflections indicate the relevance in the use of spatial relations to semantically enrich the computational applications.
\end{abstract}

Descriptors: Knowledge Organization. Knowledge organization systems. Semantic Relations. Spatial relations.

\section{REPRESENTACIÓN DE LAS RELACIONES SEMÁNTICAS EN LOS SISTEMAS DE ORGANIZACIÓN DEL CONOCIMIENTO}

\begin{abstract}
RESUMEN
Introducción: Los procesos de representación de dominios implican el establecimiento de relaciones semánticas en el marco conceptual de diferentes tipos de sistemas de organización del conocimiento (SOC). En SOC, la asociación entre conceptos se forma a partir de diferentes relaciones semánticas, presentando una estructura contextual que facilita la comprensión del conocimiento acumulado en el dominio en cuestión. Entre las diversas relaciones semánticas, las relaciones de lugar (o espacial) pueden entenderse como espacios que conectan los elementos del mundo fenomenológico. Objetivo: Este artículo presenta una investigación sobre la representación de las relaciones semánticas de lugar en SOC. Metodología: Se caracteriza por ser un estudio exploratorio y descriptivo, realizado a partir del análisis de proposiciones como un medio para determinar vínculos entre conceptos, expresando relaciones de significado entre unidades de conocimiento. Con este fin, discutimos el concepto de lugar (o espacio) en
\end{abstract}

Inf. Inf., Londrina, v. 24, n. 2, p. 139 - 162, maio/ago. 2019. 
diferentes campos del conocimiento, basado en tres enfoques de lugar: el mítico, el pragmático y el abstracto. Resultados: Como resultado, se presentan el papel y las formas de representación de las relaciones espaciales, ejemplificando con la descripción de algunas iniciativas. Conclusiones: La exploración de la literatura y las reflexiones indican la relevancia en el uso de las relaciones espaciales para enriquecer semánticamente las aplicaciones computacionales.

Descriptores: Organización del conocimiento. Sistemas de organización del conocimiento. Relaciones Semánticas. Relaciones espaciales. 